\title{
Simultaneous Determination of Ciprofloxacin and Tinidazole in Tablet Dosage Form by Reverse Phase High Performance Liquid Chromatography
}

\author{
T Sirisha $^{1 *}$, BM Gurupadayya ${ }^{1}$ and S Sridhar ${ }^{2}$ \\ ${ }^{1}$ Department of Pharmaceutical Chemistry, JSS College of Pharmacy, Mysore, ${ }^{2}$ Department of Pharmaceutical Chemistry, \\ Malla Reddy College of Pharmacy, Secunderabad, India
}

*For correspondence: Email: tadiboyina.sirisha@gmail.com; Tel: 91+8884699984

\begin{abstract}
Purpose: To develop a simple, sensitive and specific liquid chromatographic method with PDA detection for the simultaneous estimation of ciprofloxacin and tinidazole in tablet dosage form. Methods: Separation was achieved with an Agilent XDB C18, $250 \times 4.60 \mathrm{~mm} 5 \mu$ column, low pressure gradient mode with a ambient temperature and mobile phase comprising acetonitrile water containing $0.1 \%$ orthophosphoric $(20: 80)$. The flow rate was $1 \mathrm{~m} / \mathrm{min}$ and eluent was monitored spectrophotometrically at $316 \mathrm{~nm}$.

Results: The selected chromatographic conditions effectively separated ciprofloxacin and tinidazole with retention time of 3.036 and 4.224 min, respectively. Linearity for ciprofloxacin and tinidazole was in the range $50-100$ and $60-120 \mu \mathrm{g} / \mathrm{ml}$, respectively. Regression coefficient was 0.999 for both ciprofloxain and tinidazole while recovery waas $100.19-100.92$ and $99.36-100.48 \%$ for ciprofloxacin and tinidazole, respectively. Relative standard deviation (RSD) of intra- and inter-day precision was $<2$ $\%$ for both drugs.

Conclusion: The developed method is precise, accurate, reproducible and specific and it can also be used for routine simultaneous quality-control analysis of ciprofloxacin and tinidazole in combination tablets.
\end{abstract}

Keywords: High performance liquid chromatography, Ciprofloxacin, Tinidazole, Simultaneous determination.

Tropical Journal of Pharmaceutical Research is indexed by Science Citation Index (SciSearch), Scopus, International Pharmaceutical Abstract, Chemical Abstracts, Embase, Index Copernicus, EBSCO, African Index Medicus, JournalSeek, Journal Citation Reports/Science Edition, Directory of Open Access Journals (DOAJ), African Journal Online, Bioline International, Open-J-Gate and Pharmacy Abstracts

\section{INTRODUCTION}

Ciprofloxacin, 1-cyclopropyl-6-fluoro-4-oxo-7(piperazin-1-yl)-quinoline-3-carboxylic acid is a second generation fluoroquinolone. The bactericidal action of ciprofloxacin results from inhibition of the enzymes topoisomerase II (DNA gyrase) and topoisomerase IV, which are essential for bacterial transcription, repair, DNA replication, strand supercoiling repair, and recombination. Literature search reveals various methods for the estimation of ciprofloxacin alone and its combination by high performance liquid chromatography [1-4], UV [5-7], capillary zone electrophoresis [8]. Tinidazole, 1-(2ethylsulfonylethyl)-2-methyl-5-nitro-imidazole, is an anti-protozoal agent. Tinidazole is a prodrug and the anti-protozoal action of tinidazole results from reduction of nitro group of tinidazole in Trichomonas by a ferredoxin-mediated electron transport system. As a result of this reduction, a free nitro radical is generated and is believed to be responsible for the antiprotozoal activity. These toxic free radicals covalently bind to DNA, 
resulting in DNA damage and leads to cell death. The activity of tinidazole against Giardia and Entamoeba species is not known, though it is probably similar. Literature search reveals various methods for the estimation of tinidazole alone and its combination by high performance liquid chromatography [9-12] and UV [13].

The focus of the present study was to develop and validate a simple precise RP-HPLC method for the simultaneous estimation of ciprofloxacin and tinidazole.

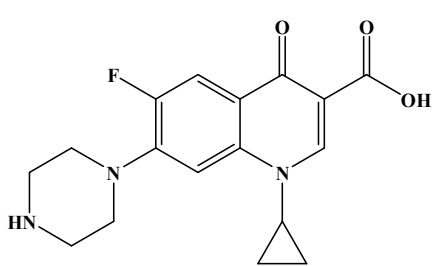

(a)

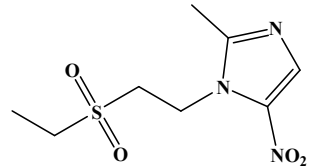

(b)
Fig 1: Structures of (a) ciprofloxacin and (b) tinidazole

\section{EXPERIMENTAL}

\section{Chemicals and reagents}

Working standards of ciprofloxacin and tinidazole were obtained from Aurbindo Laboratories, Hyderabad, India. Orthophosphoric acid AR grade was purchased from Merck. HPLC grade solvents - acetonitrile, methanol and water - were obtained from Ranchem, Mumbai, India. The pharmaceutical dosage form containing $500 \mathrm{mg}$ ciprofloxacin and $600 \mathrm{mg}$ tinidazole, Alcipro-TN $500 \mathrm{mg} / 600 \mathrm{mg}$ (Alkem) was purchased from a local drug store.

\section{Instrumentation}

The development and validation of the assay was performed on an Alliance WATERS 2695 with high speed auto sampler, column oven, degasser, 2996 PDA detector and a class Empower-2 software. Chromatographic analysis was performed on Agilent XDB (C18) RP Column, $150 \mathrm{~mm} \times 4.6 \mathrm{~mm}$ particle size 5 micron size column. The flow rate was $1 \mathrm{~mL}$ min-1, injection volume was $10 \mu \mathrm{L}$, and UV detection was performed at $316 \mathrm{~nm}$. Peak identity was confirmed by both retention time comparison and comparison of spectra obtained from the UV detector.

\section{Standard preparation}

Accurately, $25 \mathrm{mg}$ of Ciprofloxacin and $30 \mathrm{mg}$ of Tinidazole were taken into a $25 \mathrm{ml}$ volumetric flask. Then $20 \mathrm{~mL}$ of diluents was added to it and sonicated for 2 min and made up to volume (i.e., $25 \mathrm{~mL}$ ) with mobile phase and filtered through $0.45 \mu$ membrane filter and diluted to get the stock solution (1000 $\mu \mathrm{g} / \mathrm{mL}$ ciprofloxacin and $1200 \mu \mathrm{g} / \mathrm{mL}$ tinidazole) as per formulation composition.

\section{Preparation of calibration plot}

Into a series of $10 \mathrm{ml}$ volumetric flasks containing aliquots of ciprofloaxcin and tinidazole, standard stock solutions equivalent to $25-125 \mu \mathrm{g} / \mathrm{mL}$ ciprofloxacin and $30-150 \mu \mathrm{g} / \mathrm{mL}$ tinidazole were prepared with mobile phase, sonicated and filtered through $0.45 \mu$ membrane filter. Each solution was injected in triplicate and chromatographed under the chromatographic conditions specified above. Linear relationships were obtained when standard peak area ratios were plotted against the corresponding concentrations for each drug.

\section{Sample preparation}

Twenty tablets of commercial formulation containing ciprofloxacin and tinidazole (AlciproTN) were taken and powered. The powder equivalent to $10 \mathrm{mg}$ and $12 \mathrm{mg}$ of ciprofloxacin and tinidazole, respectively, was dissolved in 10 $\mathrm{ml}$ of diluent to get a stock solution of 1000 and $1200 \mu \mathrm{g} / \mathrm{mL}$ of ciprofloxacin and tinidazole, respectively, and then sonicated for $30 \mathrm{~min}$. This solution was filtered through a Whatman filter paper no. 4. From the filtrate, $0.5 \mathrm{~mL}$ was taken and further diluted with diluent up to $10 \mathrm{ml}$, which contains 50 and $60 \mu \mathrm{g} / \mathrm{mL}$ of ciprofloxacin and tinidazole, respectively, was used for the analysis.

\section{Method validation}

\section{Linearity}

The linearity of the method was evaluated by analyzing different concentration of the drugs. According to International Conference on Harmonisation ( $\mathrm{ICH}$ ) recommendations, at least five concentrations must be used [14]. In the present study, five concentrations were chosen, in the ranges of $25-125$ and $30-150 \mu \mathrm{g} / \mathrm{mL}$ for ciprofloxacin and tinidazole, respectively.

\section{Accuracy and precision}

The accuracy of the method was determined by recovery experiments using the standard addition method. The solutions were injected in triplicate and percent recovery was calculated. The precision of the method was determined by studying intra-day and inter-day variation. In the 
inter-day studies, standard and sample solutions were analysed in triplicate on three consecutive days, and percent relative standard deviation RSD calculated. In the intra-day studies, standard and sample solutions were analyzed in triplicate on the same day and percentage RSD was calculated.

\section{Limit of detection (LOD) and limit of quantitation (LOQ)}

In accordance with $\mathrm{ICH}$ recommendations, the method based on the standard deviation of the response and the slope of the calibration plots was used to determine the detection and quantification limits [15]. LOD and LOQ values were estimated as [(standard deviation of repeatability)/(Slope of the regression equation)] by multiplying with 3.3 and 10 , respectively.

\section{Specificity}

The specificity of the method was evaluated by assessing whether excipients present in the pharmaceutical formulations interfered with the analysis. Excipients for each tablet were mixed in order to prepare a placebo and solutions were prepared by following the procedure described in the section on sample preparation.

\section{Robustness}

Robustness is a measure of capacity of analytical methods to remain unaffected by small but deliberate variation of the operating conditions. This was tested by studying the effect of changing mobile phase $\mathrm{pH}$ by 0.2 , the amount of buffer in the mobile phase by $2 \%$ and detector wavelength by $2 \mathrm{~nm}$.

\section{Stability}

The sample and standard solutions injected at 0 h (comparison sample) and after $24 \mathrm{~h}$ (stability sample) by keeping at ambient room temperature. Stability was determined by determining RSD for sample and standard solutions.

\section{Statistical analysis}

Wherever applicable, results were expressed as the Mean \pm SD, $\%$ RSD and data were analyzed statistically by using t-test with aid of Microsoft excel-2007 software and data were considered significantly different at $5 \%$ significance level of probability $(p \leq 0.05)$.

\section{RESULTS}

To establish and validate an efficient method for analysis of these drugs in pharmaceutical formulations and with the objective of selecting optimum chromatographic conditions, some preliminary tests were performed. The separation was tried using either columns described previously in the literature or alternative stationary phases. Lack of resolution between ciprofloxacin and tinidazole was encountered as the main problem during these investigations. To solve these problems, three different types of C18 columns with different configurations, were used for simultaneous determination of the drugs. Good peak shape without excessive tailing and best resolution were obtained by using the Agilent XBD C18 column.

The effects of mobile phase composition, $\mathrm{pH}$ and flow rate were also studied. The best resolution along with reasonable retention time was obtained with mobile phase containing acetonitrile, and $0.1 \%$ of ortho phosphoric acid buffer $\mathrm{pH} 3.0(20: 80)$ with $1.0 \mathrm{~mL} / \mathrm{min}$ flow rate. A major reason for using a concentration of $0.1 \%$ was to achieve maximum sensitivity of UV detection at low wavelengths. The detector was set at $316 \mathrm{~nm}$ to increase the sensitivity of the method. The separation of the compounds was complete, which indicates that the method is specific as illustrated in Figs. 3 and 4. Average retention times for ciprofloxacin and tinidazole were, 3.036 and $4.224 \mathrm{~min}$, respectively, for six replicates.

\section{System suitability}

The RSD values of peak area and retention time for drugs are within 2 indicating the suitability of the system (Table 1 ).

\section{Linearity}

The calibration curves were prepared by plotting the peak areas of the drug against concentration which were linear in the range of $25-125$ and 30 - $150 \mu \mathrm{g} / \mathrm{mL}$ for ciprofloxacin and tinidazole, respectively. The calibration equations and correlation coefficients were calculated by subjecting peak area ratios and concentrations to least square linear regression analysis. The mean regression equations were found as $y=$ $11604 x+15949$ and $r^{2}=0.9991$ for ciprofloxacin and $y=15038 x+22878$ and $r^{2}=0.9995$ for tinidazole, respectively. Based on the linearity equation, $y=a x+b$, " $y$ " is the peak area ratio of 
drugs, "a" is the slope, "b" is the intercept and " $x$ " is the concentration of the measured solution in $\mu \mathrm{g} / \mathrm{mL}$. The result shows that there is excellent correlation between the peak area ratio and the concentration of drugs in the range tested.

\section{LOD and LOQ}

The LOD was $0.0587 \mu \mathrm{g} / \mathrm{mL}$ for ciprofloxacin and $1.0667 \mu \mathrm{g} / \mathrm{mL}$ for tinidazole. The limit of quantification was determined as $0.1779 \mu \mathrm{g} / \mathrm{mL}$ for ciprofloxacin and $3.232 \mu \mathrm{g} / \mathrm{mL}$ for tinidazole.

\section{Precision}

Intra-day precision was performed by relative standard deviation of five repeated assays of samples at the three concentration levels. Interday precision was determined by analyzing the same set of samples for five different days. The RSD values were found to be $0.226-1.928 \%$ for ciprofloxacin and $0.420-1.187 \%$ for tinidazole, respectively, indicating good precision (Table 2).

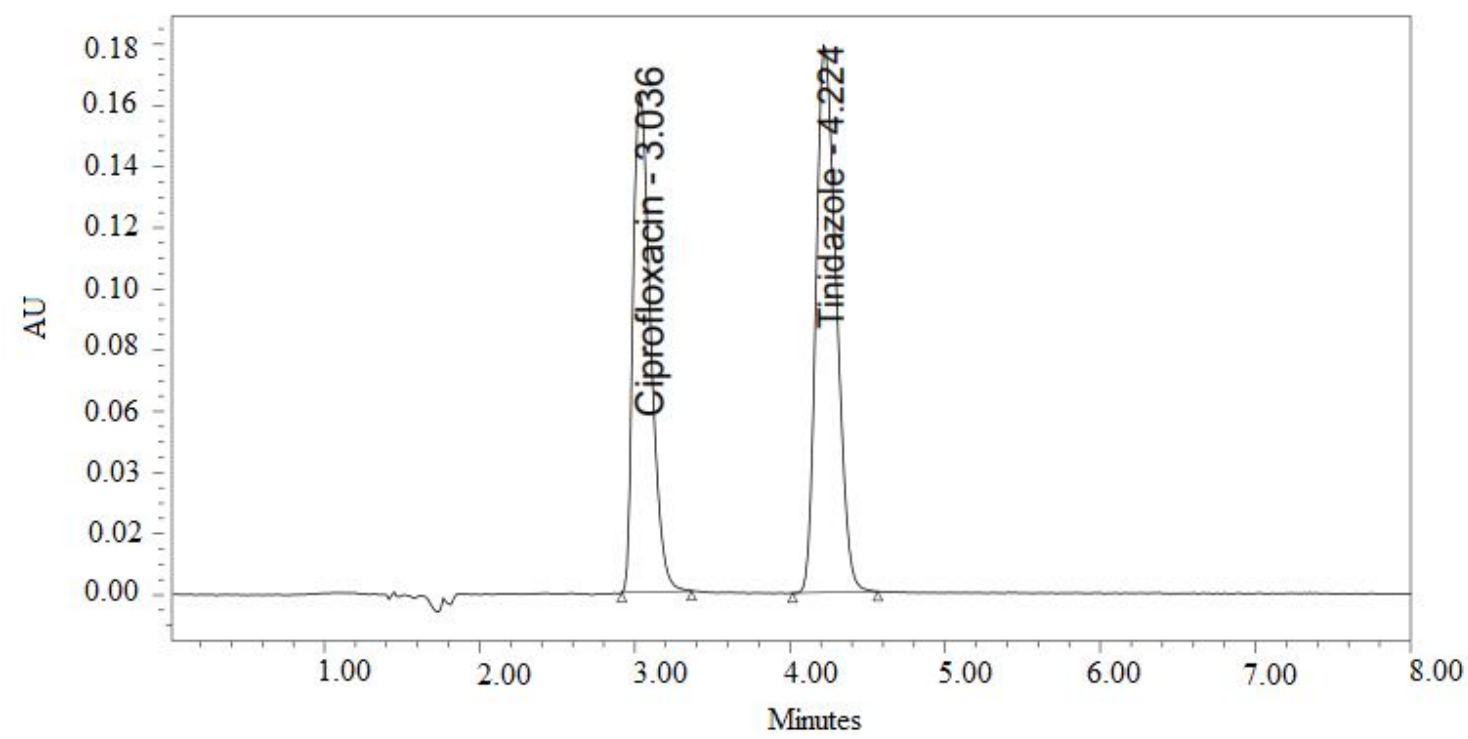

Fig 3: HPLC chromatogram of pure ciprofloxacin and tinidazole

Table 1: Results of system suitability study

\begin{tabular}{lcccc}
\hline & \multicolumn{2}{c}{ Ciprofloxacin } & \multicolumn{2}{c}{ Tinidazole } \\
\cline { 2 - 5 } Mean & Retention time (min) & Peak area & Retention time (min) & Peak area \\
\cline { 2 - 5 } SD & 3.1673 & 596289 & 4.2208 & 925708 \\
RSD & 0.035 & 1686 & 0.0523 & 3562 \\
& 1.13 & 0.35 & 1.24 & 0.48 \\
\hline
\end{tabular}

Table 2: Intra- and inter-day precision and accuracy of ciprofloxacin and tinidazole

\begin{tabular}{|c|c|c|c|c|c|}
\hline \multirow[t]{2}{*}{ Drug } & \multirow{2}{*}{$\begin{array}{c}\text { Actual } \\
\text { concentration } \\
(\mu \mathrm{g} / \mathrm{mL})\end{array}$} & \multicolumn{2}{|c|}{ Intra-day } & \multicolumn{2}{|c|}{ Inter-day } \\
\hline & & $\begin{array}{c}\text { Found } \\
\text { concentration } \\
(\mu g / m L) \pm S D\end{array}$ & RSD (\%) & $\begin{array}{c}\text { Found } \\
\text { concentration } \\
(\mu g / m L) \pm S D\end{array}$ & RSD (\%) \\
\hline \multirow[t]{6}{*}{ CIPRO } & 25 & $25.144 \pm 0.177$ & 0.707 & $24.888 \pm 0.479$ & 1.928 \\
\hline & & $19.910 \pm 0.383$ & 1.928 & $20.115 \pm 0.142$ & 0.707 \\
\hline & 50 & $50.657 \pm 0.381$ & 0.752 & $50.130 \pm 0.113$ & 0.226 \\
\hline & & $40.104 \pm 0.090$ & 0.226 & $40.525 \pm 0.305$ & 0.752 \\
\hline & 75 & $75.050 \pm 0.967$ & 0.967 & $75.573 \pm 0.470$ & 0.622 \\
\hline & & $60.458 \pm 0.376$ & 0.622 & $60.040 \pm 0.580$ & 0.967 \\
\hline \multirow[t]{6}{*}{ TINI } & 30 & $29.805 \pm 0.210$ & 0.705 & $29.678 \pm 0.352$ & 1.187 \\
\hline & & $23.742 \pm 0.282$ & 1.187 & $23.844 \pm 0.168$ & 0.705 \\
\hline & 60 & $59.666 \pm 0.250$ & 0.420 & $59.768 \pm 0.404$ & 0.677 \\
\hline & & $47.815 \pm 0.323$ & 0.677 & $47.733 \pm 0.200$ & 0.420 \\
\hline & 90 & $90.824 \pm 0.525$ & 0.578 & $90.884 \pm 0.766$ & 0.843 \\
\hline & & $72.707 \pm 0.613$ & 0.843 & $72.659 \pm 0.420$ & 0.578 \\
\hline
\end{tabular}


Table 3: Student t- test data for precision results of ciprofloxacin and tinidazole

\begin{tabular}{lcccc}
\hline $\begin{array}{l}\text { Validation } \\
\text { parameter }\end{array}$ & \multicolumn{2}{c}{ Ciprofloxacin } & \multicolumn{2}{c}{ Tinidazole } \\
\cline { 2 - 5 } & Mean response & $\begin{array}{c}\text { Probability } \\
(\geq 0.05)\end{array}$ & Mean response & $\begin{array}{c}\text { Probability } \\
(\geq 0.05)\end{array}$ \\
\hline Day 1 & 596649.8 & 0.491 & 925554.7 & 0.018 \\
Day 2 & 596516.8 & & 925120.5 & \\
\hline
\end{tabular}

Table 4: Results of recovery studies by standard addition method

\begin{tabular}{|c|c|c|c|c|c|}
\hline Name of the drug & $\begin{array}{l}\text { Amount of } \\
\text { drug in tablet } \\
(\mu \mathrm{g} / \mathrm{mL})\end{array}$ & $\begin{array}{l}\text { Amount of pure } \\
\text { drug added } \\
(\mu \mathrm{g} / \mathrm{mL})\end{array}$ & $\begin{array}{l}\text { Total found }(\mu \mathrm{g}) \\
\text { (Mean } \pm \text { SD) }\end{array}$ & RSD (\%) & Recovery (\%) \\
\hline \multirow[t]{6}{*}{ Ciprofloxacin } & 50 & 25 & $75.1575 \pm 0.194$ & 0.323 & 100.21 \\
\hline & 40 & 20 & $60.0421 \pm 0.194$ & & \\
\hline & 50 & 50 & $100.19 \pm 0.662$ & 0.827 & 100.19 \\
\hline & 40 & 40 & $80.0763 \pm 0.662$ & & \\
\hline & 50 & 75 & $126.15 \pm 0.592$ & 0.588 & 100.92 \\
\hline & 40 & 60 & $100.5535 \pm 0.592$ & & \\
\hline \multirow{6}{*}{ Tinidazole } & 60 & 30 & $90.432 \pm 0.262$ & 0.364 & 100.48 \\
\hline & 48 & 24 & $72.1158 \pm 0.262$ & & \\
\hline & 60 & 60 & $120 \pm 0.014$ & 0.015 & 100.00 \\
\hline & 48 & 48 & $96.0011 \pm 0.014$ & & \\
\hline & 60 & 90 & $149.04 \pm 0.660$ & 0.552 & 99.36 \\
\hline & 48 & 72 & $119.5463 \pm 0.660$ & & \\
\hline
\end{tabular}

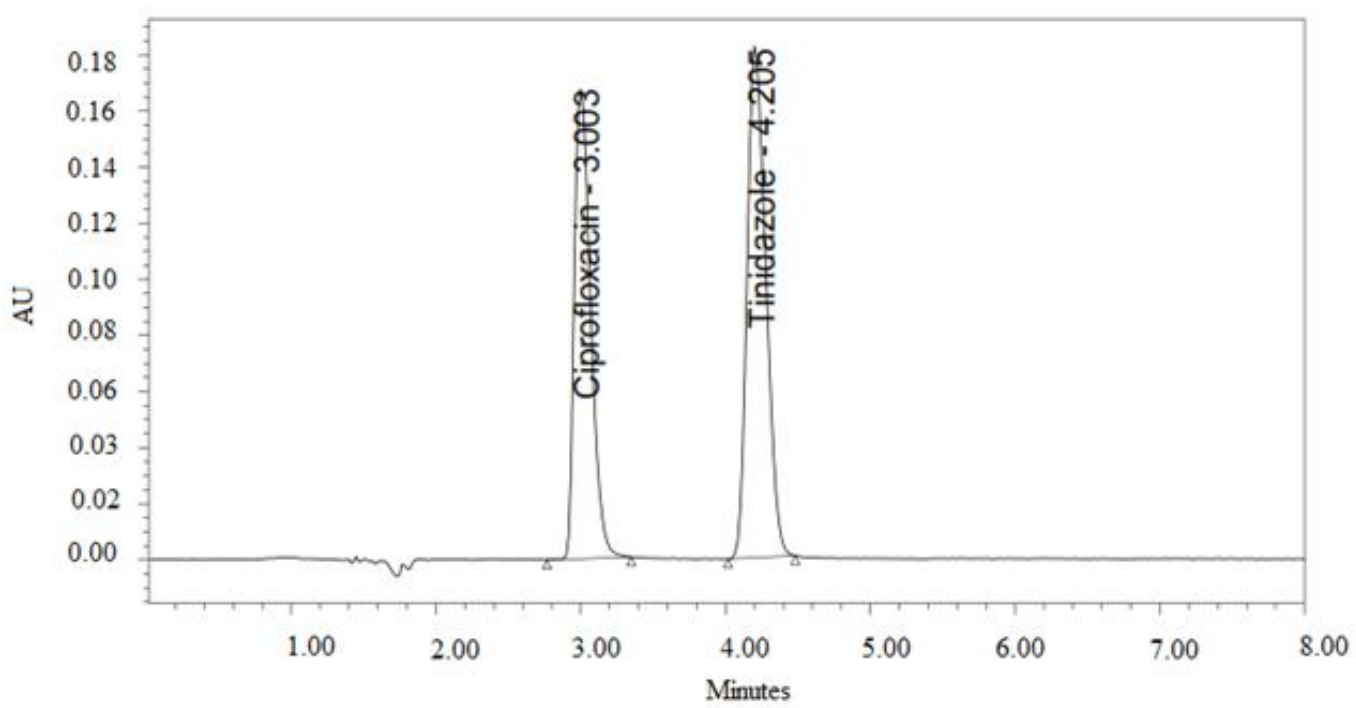

Fig. 4: HPLC chromatogram for tablet formulation

\section{Statistics}

The probability value $(P)$ for ciprofloxacin and tinidazole at $5 \%$ significance level was 0.209 and 0.229 , respectively. The $p$ values were $>$ 0.05 and hence there was no significant difference between the precision results carried out on two consecutive days. The results are shown in Table 3.

\section{Recovery}

To examine the accuracy of the method, recovery studies were carried out by standard addition method. The percent recovery of the added standard to the assay samples was calculated from:

Recovery \% $=\{(\mathrm{C} 1-\mathrm{Cu}) / \mathrm{Ca}\} 100$

where $\mathrm{C} 1$ is the total concentration of analyte found; $\mathrm{Cu}$ is the concentration analyte present in the formulation; and $\mathrm{Ca}$ is the concentration added to the formulation. The average percent recoveries obtained as 99.36 - $100.92 \%$ indicate good accuracy of the method (Table 4)

\section{Specificity}

The specificity was determined by the complete separation of ciprofloxain and tinidazole as

Trop J Pharm Res, June 2014; 13(6): 985 
shown in Figs. 3 and 4 with parameters like retention time $(\mathrm{Rt})$, resolution $(\mathrm{Rs})$ and tailing factor $(T)$. The peaks obtained showed that there is no blank and placebo interference with that of the main peaks.

\section{Robustness}

To ensure the insensitivity of the HPLC method to minor changes in the experimental conditions, it is important to demonstrate robustness of the method. None of the modifications caused a significant change in the resolution between the drugs, peak area RSD, USP tailing factor, peak width or theoretical plates.

\section{Stability of sample solution}

The sample and standard solutions were injected at $0 \mathrm{~h}$ (comparison sample) and after $24 \mathrm{~h}$ (stability sample) and keeping at ambient room temperature $30{ }^{\circ} \mathrm{C}$. RSD for 0 and $24 \mathrm{~h}$ for sample and standard solutions of ciprofloxacin are $1.23,0.94$ and $1.87,0.64$, respectively. RSD for 0 and $24 \mathrm{~h}$ for sample and standard solutions of tinidazole is 1.27, 0.97 and 1.73, 0.66, respectively. RSD results for both ciprofloxacin and tinidazole are within the limit of $\leq 2$ and hence the sample and standard stock are stable for $24 \mathrm{~h}$ at ambient room temperature

\section{Assay}

The proposed method was used to estimate the total drug content in commercially available pharmaceutical dosage forms. The results obtained are in agreement with the claimed amounts of the tablet dosage form (Alcipro-TN) and results were shown in Table 5 .

Table 5: Assay results for commercial tablets (AlciproTN)

\begin{tabular}{lcc}
\hline Drug & Claimed $\mathbf{( m g )}$ & Found \pm SD $(\mathbf{m g})$ \\
\hline Ciprofloxacin & 500 & $497.32 \pm 0.19$ \\
Tinidazole & 600 & $601.35 \pm 0.11$ \\
\hline
\end{tabular}

\section{DISCUSSION}

Recovery of ciprofloxacin and tinidazole was 100.44 and $99.94 \%$, respectively, and it shows that the proposed method is accurate. The regression coefficient value is 0.999 for both ciprofloxacin and tinidazole and thus the response is linear. Repeatability and intermediate precision values were within the acceptable limits. This indicates that the method is precise. The resolution between two peaks is always $>2$. The lowest values of LOD and LOQ as obtained by the proposed method indicate that the method is sensitive. The solution stability studies indicate that both the drugs were stable up to $24 \mathrm{~h}$. Change in flow rate, temperature and mobile phase composition did not cause any significant change in results shows reliability of the development method.

\section{CONCLUSION}

A simple, rapid, and reliable LC method has been established for the simultaneous determination of ciprofloxacin and tinidazole either alone or in their binary formulations. The method has several advantages, including rapid analysis, a simple mobile phase, simple sample preparation, and improved sensitivity. It is suitable for analysis of these drugs in their binary formulations in a single isocratic run, in contrast with previous methods. This makes the method suitable for routine analysis of the combination product in quality-control laboratories.

\section{ACKNOWLEDGEMENT}

The authors would like to thank the Principal and Management, JSS College of Pharmacy, Mysore, India for providing laboratory facilities to carry out this work.

\section{REFERENCES}

1. Manoranjan S, Sharada N, Venkateswarlu G, Sravan PM, Praveena KM, Madhu CS. A new analytical method development and validation for estimation of Ciprofloxacin in bulk and pharmaceutical dosage form. Asian J Pharm Anal 2012; 2(4): 116-117.

2. Simmy OT, Admin PD. Stability indicating reversedphase liquid chromatographic determination of ciprofloxacin as bulk drug and in pharmaceutical formulations. J Pharma Biomed Anal 2000; 22: 699703.

3. Claudia G, Laura M, John S, Douglas GJ, Sergio F, Sanchez B. A liquid chromatographic method, with fluorometric detection, for the determination of Enrofloxacin and Ciprofloxacin in plasma and endometrial tissues of mares. Anal Chim Acta 2006; 560: 227-234.

4. Andrzej $P$, Jan Z, Jolanta NZ. Liquid chromatography analysis of enrofloxacin and ciprofloxacin in chicken blood spotted on filter paper disks. J Chromatogr $B$ 2002; 780: 309-314.

5. Isabel PMR, Gertrudis PP, Antonia MD. Solid-Phase UV Spectrophotometric method for determination of Ciprofloxacin. Microchemical J. 2004; 77: 79-84. 
6. Patel SA, Patel NM, Patel MM. Simultaneous spectrophotometric estimation of ciprofloxacin and ornidazole in tablets. Ind J Pharma Sci 2006; 68(5): 665-667.

7. Sowjanya G, Devi T, Sri VV, Pratyusha V, Venkata LNSRJ. Development and validation of $u v$ spectroscopic methods for simultaneous estimation of ciprofloxacin and tinidazole in tablet formulation. Int Current pharma J 2012; 1(10): 317-321.

8. Katarzyna M, Genowefa P, Stefan T. Determination of Ciprofloxacin and its impurities by capillary zone electrophoresis. J Chromatogr A 2004; 1051: $267-$ 272.

9. Jukka PS, Hannele S. High performance thin layer chromatographic analysis of hydrolyzed tinidazole solutions. J Pharma Biomed Anal 1996; 14: 1261 1266.

10. Alton KB, Patrick JE. High performance liquid chromatographic assay for antiprotozoal agent, tinidazole in human plasma. J Pharma Sci 1979; 68(5): 599-601.

11. Pai PNS, Rao GK, Srinivas B, Puranik S. RPLC determination of tinidazole and diloxanide furoate in tablets. Ind J Pharma Sci 2008; 70(5): 670-672.

12. Prasad CVN, Sripriya V, Saha RN, Parimoo $P$. Simultaneous determination of tinidazole, furazolidone and diloxanide furoate in a combined tablet preparation by second- derivative spectrophotometry. J Pharma Biomed Anal 1999; 21: 961-968.

13. Hackett $L P$, Dusci LJ. Determination of metronidazole and tinidazole in human plasma using high performance liquid chromatography. J Chromatogr 1979; 175: 347-349.

14. Validation of analytical procedures: Text and methodology Q2 (R1). ICH Harmonised Tripartite Guidelines.1996. 